\title{
ANALISIS PENDAPATAN USAHA PETERNAKAN AYAM BURAS (Studi Kasus di Kecamatan Tegalombo, Kabupaten Pacitan)
}

\section{INCOME ANALYSIS OF NATIVE CHICKEN FARMING (Case Study in Sub-District Tegalombo, Pacitan)}

\author{
Ratih Dewanti* dan Ginda Sihombing \\ Jurusan Peternakan, Fakultas Pertanian, Universitas Sebelas Maret, Jl. Ir. Sutami 36a, Kentingan, Surakarta, 57126
}

\section{INTISARI}

Penelitian bertujuan untuk mengetahui besarnya pendapatan yang diperoleh peternak ayam buras dan pengaruh faktor-faktor produksi terhadap pendapatan usaha peternakan ayam buras di Kecamatan Tegalombo Kabupaten Pacitan. Penelitian dilaksanakan di Desa Kemuning, Desa Tegalombo dan Desa Tahunan mulai tanggal 3 Januari sampai 4 Februari 2011. Metode yang digunakan dalam penelitian adalah metode survei dengan wawancara langsung kepada 30 peternak dan pengambilan lokasi dilakukan secara sengaja (purposive sampling). Data yang dikumpulkan ditabulasi kemudian dianalisis untuk mengetahui pendapatan. Analisis data dilakukan dengan menggunakan fungsi keuntungan dengan teknik Unit Output Price Cobb-Douglas Profit Function (OUP-CDPF) melalui analisis regresi berganda (alat bantu software Econometric Views/Eviews) dan dilanjutkan dengan uji $\mathrm{F}$ dan uji t. Hasil penelitian menunjukkan bahwa rata-rata pendapatan bersih dari penjualan ayam buras 89 ekor, feses dan telur yaitu Rp. 1.383.358,10 per tahun/peternak. Berdasarkan analisis regresi linear berganda diperoleh persamaan $\hat{Y}=20,947+0,620 \mathrm{X}_{1}+0,003 \mathrm{X}_{2}$ $0,996 \mathrm{X}_{3}-0,869 \mathrm{X}_{4}-0,015 \mathrm{X}_{5}+0,845 \mathrm{X}_{6}$. Nilai koefisien determinasi $\left(\mathrm{R}^{2}\right)$ sebesar 0,646 berarti pendapatan ayam buras mampu dijelaskan oleh biaya pembelian ayam, jagung, dedak, obat/vitamin, tenaga kerja, listrik sebesar $64,6 \%$ sedangkan sisanya sebesar $35,4 \%$ dipengaruhi oleh variabel-variabel di luar yang diteliti. Pada uji $\mathrm{F}$, variabel independen (biaya pembelian ayam, jagung, dedak, obat/vitamin, tenaga kerja, dan listrik) berpengaruh secara bersama terhadap variabel dependen dengan tingkat signifikan 0,05 , berdasarkan uji $t$ faktor biaya pendapatan dipengaruhi oleh pembelian ayam dan biaya listrik sedangkan biaya lainnya (biaya jagung, obat/vitamin, dan tenaga kerja) tidak berpengaruh terhadap pendapatan usaha peternakan ayam buras di Kecamatan Tegalombo, Kabupaten Pacitan.

(Kata kunci: Analisis pendapatan, Ayam buras, Regresi berganda)

\section{ABSTRACT}

This research aimed to identify the amount of income level obtained by native-chicken farmer and the influence of costs of production toward the income of the farmers in sub-district Tegalombo, Pacitan. This research was conducted in Kemuning village, Tegalombo village dan Tahunan village started from January $3^{\text {rd }}$ to February $4^{\text {th }} 2011$. The method used in this research was survey method by interviewing 30 farmers and the location was selected by purposive sampling technique. The data were collected, tabulated and then analyzed to determine the income. The data were analyzed by the advantage function with Output Price Unit Cobb-Douglas Profit Function (OUP-CDPF) technique and then continued with $F$ test and $T$ test. The results of this research showed that the average net incomes from the native-chicken farmer were Rp. 1.383.358,10 in one year/farmers. Based on linear regression analysis it was obtained the equation of $\hat{Y}=20,947+0,620 X_{I}+0,003 X_{2}-0,996 X_{3}-0,869 X_{4}-0,015 X_{5}+0,845 X_{6}$. The value of the coefficient of determination $\left(R^{2}\right)=0.646$ indicated that native chicken income can be explained by the cost of purchasing chicken, corn, bran, drugs/vitamins, labor, electricity of $64.6 \%$ while the rest of $35.4 \%$ were influenced by other variables. The $F$ test, independent variables (the cost of chicken, corn, bran, drugs/vitamins, and electricity) simultaneously influenced toward the dependent variables with significant level of 0.05. Based on the T test, factor of income variables was influenced by the cost of purchasing chicken and electricity. Moreover, the other costs (corn, bran, drugs/vitamins, and labor) did not have any influence on the income of native-chicken farm production in sub-district Tegalombo, Pacitan.

(Keywords: Analysis of income, Native chicken, Multiple regression)

\footnotetext{
* Korespondensi (corresponding author):

Telp. +6285229713111

E-mail: dewa_proter@yahoo.com
} 


\section{Pendahuluan}

Ayam buras (ayam bukan ras) merupakan unggas lokal yang populasinya tersebar di seluruh wilayah Indonesia seperti ayam Kedu, Nunukan, Lampung dan Pelung. Unggas lokal tersebut berpotensi besar untuk dikembangkan karena mempunyai peranan yang sangat penting dalam memenuhi kecukupan gizi keluarga, peningkatan pendapatan keluarga dan dijadikan sebagai tabungan bagi peternak. Pemeliharaan dan pemasaran ayam buras sangat sederhana sedangkan dari pendapatan sangat menguntungkan bagi peternak (Sarwono, 1992).

Umumnya ayam buras dipelihara secara tradisional (ekstensif) kemudian dengan perkembangan ilmu pengetahuan dan kesadaran dari peternak beralih ke sistem pemeliharaan yang semi intensif, yaitu pemeliharaan yang lebih banyak memperoleh campur tangan pemiliknya dengan memberi pakan yang berkualitas, serta perbaikan sistem pemeliharaan berupa umbaran yang terbatas. Usaha peternakan ayam buras yang berorientasi ekonomi dan efisiensi perlu diintroduksikan pada petani peternak sehingga mendapatkan nilai tambah yang menjadikan ayam buras menjadi sumber pendapatan yang potensial (Yuwanta et al., 1999).

Peternakan ayam buras merupakan usaha yang didominasi oleh semua kalangan dengan modal yang sangat terbatas sehingga pengeluaran atau biaya untuk pengembangan dan pembelian ternak sering tidak dapat terpenuhi, bahkan modal kerja untuk menyediakan ternak sebagai modal awal masih banyak yang belum terpenuhi (Wiguna, 1993).

Dewasa ini telah banyak dijumpai usaha peternakan ayam buras dengan mengelola usahanya lebih memperhatikan pakan, kesehatan ternak dengan baik, hal tersebut karena ternak ayam buras sebagai sumber protein hewani dan dapat meningkatkan pendapatan bagi peternak.

Kecamatan Tegalombo merupakan daerah strategis di Kabupaten Pacitan untuk pengembangan ayam buras karena sebagian penduduknya bermata pencaharian di bidang pertanian. Usaha ternak ayam buras tidak hanya sebagai usaha sambilan tetapi juga memberikan peranan yang cukup potensial dalam meningkatkan pendapatan bagi petani peternak. Usaha ayam buras di Kecamatan Tegalombo Kabupaten Pacitan masih merupakan usaha sambilan dan belum dikelola secara optimal karena keterbatasan pengetahuan tentang usaha berternak ayam, sehingga perlu dilakukan penelitian untuk mengetahui faktor-faktor produksi (biaya pembelian ayam, pakan dedak, jagung, obat/vitamin, tenaga kerja, dan listrik) yang mempengaruhi pendapatan usaha peternakan ayam buras.

\section{Materi dan Metode}

Penelitian dilaksanakan mulai tanggal 3 Januari sampai 4 Februari 2011 di Kecamatan Tegalombo, Kabupaten Pacitan. Pengambilan sampel untuk penelitian ditentukan secara sengaja (purposive sampling).

Penelitian menggunakan metode survei dengan melalui dua tahap yaitu tahap pra survei dan tahap survei. Tahap pra survei dilakukan untuk menentukan lokasi penelitian dan peternak yang akan dijadikan responden. Tahap survei dilaksanakan untuk mengumpulkan data melalui wawancara lansung dengan responden berdasarkan daftar pertanyaan yang ada dan melihat langsung keadaan peternak.

\section{Teknik pengumpulan data}

Teknik pengumpulan data yang dipergunakan dalam penelitian yaitu observasi lapangan, wawancara, pencatatan, dan studi pustaka.

Observasi lapangan yaitu melakukan pengamatan langsung terhadap lokasi atau daerah yang menjadi obyek penelitian. Wawancara yaitu mengadakan tatap muka langsung dengan responden untuk mengumpulkan data yang diperlukan dengan menggunakan kuesioner. Pencatatan yaitu metode pengumpulan data dengan mencatat berbagai informasi yang dibutuhkan di kantor ataupun instansi yang terkait. Studi pustaka mengenai pengelolaan ayam buras pada peternak dan analisis pendapatan.

\section{Teknik pengambilan sampel}

Metode penentuan lokasi. Penentuan lokasi ditentukan dengan sengaja berdasarkan populasi ternak tinggi, sedang dan rendah untuk dijadikan lokasi sampel penelitian. Penelitian dilaksanakan di Kecamatan Tegalombo, Kabupaten Pacitan dengan mengambil 3 desa sebagai lokasi sampel penelitian yaitu Desa Kemuning, Tegalombo dan Tahunan. Populasi ayam buras di Kecamatan Tegalombo tersaji pada Tabel 1 .

Metode pengambilan sampel. Metode pengambilan sampel peternak dengan (purposive sampling) yaitu dipilih peternak di kelompok sampel yang memiliki ternak ayam buras minimal 100 ekor dalam masa produksi dan sudah dalam pemeliharaan selama setahun. Rata-rata kepemilikan ayam buras setiap peternak adalah 175 ekor, dan rata-rata populasi setiap desa adalah 5.640 ekor. Jumlah sampel 3 desa dalam penelitian adalah 30 responden dengan pengambilan secara proposional pada setiap kelompok. Sunyoto (2009) menjelaskan bahwa purposive sampling yaitu cara pengambilan sampel dengan maksud dan tujuan tertentu. 
Tabel 1. Jumlah populasi ayam buras di Kecamatan Tegalombo Kabupaten Pacitan tahun 2009 (native chicken population in sub District Tegalombo Pacitan 2009)

\begin{tabular}{lc}
\hline \hline \multicolumn{1}{c}{ Desa (village) } & Jumlah populasi ayam buras (ekor) (native chicken population (head) $)$ \\
\hline Kebondalem & 4.765 \\
Gedangan & 5.275 \\
Ngerco & 5.550 \\
Kemuning & 6.850 \\
Tegalombo & 5.700 \\
Kasihan & 5.525 \\
Pucangombo & 6.250 \\
Gemaharjo & 6.425 \\
Tahunan & 4.800 \\
Ploso & 6.275 \\
Takeran & 4.620 \\
\hline
\end{tabular}

Sumber: Dinas Peternakan dan Kesehatan Hewan Kecamatan Tegalombo, 2009 (Animal Husbandry and Veterinery Department in sub District Tegalombo, 2009).

Pengambilan sampel untuk masing-masing desa dilakukan dengan proporsional. Jumlah sampel setiap desa 10 responden dengan mengunakan rumus (Mardikanto, 2001):

Keterangan:

$$
\mathrm{Ni}=\frac{\mathrm{Nk}}{\mathrm{N}} \times 100
$$

$\mathrm{Ni}$ : jumlah sampel peternak ayam buras pada desa ke-i

Nk : jumlah peternak ayam buras pada masingmasing desa

$\mathrm{N}$ : jumlah peternak ayam buras dari semua desa

\section{Jenis dan sumber data}

Data primer (data yang diperoleh dari sumber asli). Data primer adalah data yang dikumpulkan langsung dari responden. Teknik pengumpulan data primer ini terdiri dari beberapa cara, yaitu kuesioner, wawancara, dan observasi.

Data sekunder. Data sekunder diperoleh dari jurnal, prosiding, text book, referensi internet, dokumen Dinas Peternakan dan Kesehatan Hewan Kecamatan Tegalombo (2009), dan Badan Pusat Statistik (2010).

\section{Variabel penelitian}

Variabel dalam penelitian meliputi keuntungan, biaya pembelian ayam, biaya pakan jagung, biaya pakan dedak, biaya obat dan vitamin, biaya tenaga kerja, dan biaya listrik.

Keuntungan $(\pi)$ merupakan selisih antara penerimaan (hasil penjualan) dengan biaya total yang telah dinormalkan dengan tingkat harga output.

Biaya pembelian ayam $\left(\mathrm{X}_{1}\right)$ merupakan jumlah biaya yang dikeluarkan guna keperluan pembelian ayam dalam satu masa usaha peternakan ayam buras yang dinormalkan dengan harga output.
Biaya pakan jagung $\left(\mathrm{X}_{2}\right)$ merupakan jumlah biaya yang dikeluarkan guna keperluan pembelian pakan jagung dalam satu masa usaha peternakan ayam buras yang dinormalkan dengan harga output.

Biaya pakan dedak $\left(\mathrm{X}_{3}\right)$ merupakan jumlah biaya yang dikeluarkan guna keperluan pembelian pakan dedak dalam satu masa usaha peternakan ayam buras yang dinormalkan dengan harga output.

Biaya obat dan vitamin $\left(\mathrm{X}_{4}\right)$ merupakan jumlah biaya yang dikeluarkan guna keperluan pembelian obat-obatan dan vitamin dalam satu masa usaha peternakan ayam buras yang dinormalkan dengan harga output.

Biaya tenaga kerja $\left(\mathrm{X}_{5}\right)$ merupakan biaya rata-rata tenaga kerja yang dikeluarkan oleh peternak yang dinyatakan dalam rupiah per satu masa usaha peternakan ayam buras dibagi dengan harga output, diukur dalam satuan rupiah.

Biaya listrik $\left(\mathrm{X}_{6}\right)$ merupakan jumlah biaya yang dikeluarkan guna keperluan penerangan bagi ayam buras dalam masa usaha peternakan ayam buras yang dinormalkan dengan harga output.

\section{Teknik analisis data}

Analisis data hipotesis pertama. Hipotesis pertama adalah usaha peternakan ayam buras di Kecamatan Tegalombo, Kabupaten Pacitan menguntungkan bagi peternak. Biaya, penerimaan, dan keuntungan usaha pemeliharaan ayam buras dapat dihitung dengan rumus (Soekartawi, 2003):

$$
\pi=\mathrm{TR}-\mathrm{TC}
$$

\section{Keterangan :}

$\pi=$ pendapatan dari usaha pemeliharaan ayam buras (Rp)

$\mathrm{TR}=$ penerimaan total usaha dari hasil pemeliharaan ayam buras $(\mathrm{Rp})$

$\mathrm{TC}=$ biaya total usaha dari hasil pemeliharaan ayam buras (Rp). 
Analisis hipotesis kedua. Hipotesis kedua adalah faktor-faktor produksi berpengaruh terhadap pendapatan usaha ayam buras di Kecamatan Tegalombo, Kabupaten Pacitan. Analisis kedua diuji dengan menggunakan fungsi keuntungan dengan teknik Unik output price Cobb-Douglas Profit Function (OUP-CDPF) melalui analisis regresi berganda dengan alat bantu Softwart Econometric Views (Eviews).

Penyelesaian hubungan antara $\mathrm{Y}$ dan $\mathrm{X}$ adalah dengan cara regresi yaitu variasi dari $\mathrm{Y}$ akan dipengaruhi oleh variasi dari $\mathrm{X}$ dengan model pendugaan menggunakan fungsi Cobb-Douglas dapat dituliskan sebagai berikut:

$$
\mathrm{Y}=\mathrm{a}+\mathrm{b}_{1} \mathrm{X}_{1}+\mathrm{b}_{2} \mathrm{X}_{2}+\mathrm{b}_{3} \mathrm{X}_{3}+\mathrm{b}_{4} \mathrm{X}_{4}+\mathrm{b}_{5} \mathrm{X}_{5}+\mathrm{b}_{6} \mathrm{X}_{6}+\mathrm{ei}
$$

Keterangan:

$\mathrm{Y}=$ pendapatan peternak ayam buras (Rp/tahun)

a $=$ konstanta

$\mathrm{b} \quad=$ koefisien regresi

$\mathrm{X}_{1}=$ biaya pembelian ayam (Rp/tahun)

$\mathrm{X}_{2}=$ biaya pakan jagung (Rp/tahun)

$\mathrm{X}_{3}=$ biaya pakan dedak (Rp/tahun)

$\mathrm{X}_{4}=$ biaya obat dan vitamin (Rp/tahun)

$\mathrm{X}_{5}=$ biaya tenaga kerja (Rp/tahun)

$\mathrm{X}_{6}=$ biaya listrik (Rp/tahun)

ei $=$ faktor-faktor pengganggu

Persamaan tersebut diubah menjadi bentuk linier berganda dengan cara melogaritmakan persamaan tersebut, agar memudahkan pendugaan terhadap persamaan di atas. Bentuk logaritma dari persamaan di atas adalah (Soekartawi, 2003):

$\log Y=\log a+b_{1} \log X_{1}+b_{2} \log X_{2}+\ldots b_{n} \log X_{n}+u$

Koefisien masing-masing variabel diperoleh dan selanjutnya adalah dilakukan uji asumsi klasik dan uji statistik untuk menentukan tingkat signifikannya. Uji asumsi klasik yang dilakukan meliputi uji multikolinieritas dan heterokedastisitas.

Uji multikolinieritas diterapkan untuk menganalisis regresi berganda yang terdiri dari dua atau lebih variabel bebas atau independent variable $\left(\mathrm{X}_{1}, \mathrm{X}_{2}, \mathrm{X}_{3}, \mathrm{X}_{4}, \ldots, \mathrm{X}_{\mathrm{n}}\right)$, di mana akan diukur tingkat asosiasi (keeratan) hubungan atau pengaruh antar variabel bebas tersebut melalui besarnya koefisien korelasi (r). Multilinieritas terjadi jika koefisien antar variabel bebas $\left(\mathrm{X}_{1}\right.$ dan $\mathrm{X}_{2}, \mathrm{X}_{2}$ dan $\mathrm{X}_{3}, \mathrm{X}_{3}$ dan $\mathrm{X}_{4}$ dan seterusnya) lebih besar dari 0,60 (pendapat lain 0,50 dan 0,90). Multilinieritas tidak terjadi jika koefisien korelasi antar variabel bebas lebih kecil atau sama dengan 0,60 $(r<0,60)$. Nilai $r^{2}>R^{2}$ berarti tidak ada gejala multilinieritas, tetapi jika $\mathrm{r}^{2}$ $<\mathrm{R}^{2}$ maka model tersebut mengandung masalah multilinieritas (Gujarati, 1999).

Uji heterokedastisitas diterapkan untuk mengetahui sama atau tidaknya varian dari residual dari observasi yang satu dengan observasi yang lain. Residualnya mempunyai varian yang sama disebut terjadi homoskedastisitas. Persamaan regresi yang baik adalah tidak terjadi homoskedastisitas. Analisis uji asumsi homoskedastisitas hasil output Eviews melalui grafik scatterplot antara $\mathrm{Z}$ prediction (ZPRED) yang merupakan variabel bebas (sumbu $\mathrm{x}$ $=\mathrm{y}$ hasil prediksi) dan nilai residualnya (SRESID) merupakan variabel terikat (sumbu $\mathrm{Y}=\mathrm{Y}$ prediksi Y riil).

Homoskedastisitas terjadi jika pada scatterplot (lihat Gambar Scatterplot test) titik-titik hasil pengolahan data antara ZPRED dan SRESID menyebar di bawah ataupun di atas titik origin (angka 0) pada sumbu Y yang tidak mempunyai pola yang teratur. Homoskedastisitas terjadi jika pada scatterplot titik-titiknya mempunyai pola yang teratur, baik menyempit, melebar maupun bergelombang-gelombang (Sunyoto, 2009).

Uji statistik yang dilakukan meliputi uji $\mathrm{F}$, $\mathrm{R}^{2}$, dan t. Uji F (Fisher test) digunakan agar dapat mengetahui adanya pengaruh variabel independen secara bersama-sama terhadap variabel dependen secara signifikan atau tidak (Gujarati, 1999).

$\mathrm{R}^{2}$ (koefisien determinasi) digunakan untuk menunjukkan sampai seberapa besar variansi variabel independen yang dapat dijelaskan oleh variansi dari variabel dependen. Nilai $\mathrm{R}^{2}$ dapat dihitung sebagai berikut (Gujarati, 1999):

$$
\begin{aligned}
\mathrm{R}^{2} & =\frac{\mathrm{ESS}}{\mathrm{TSS}} \\
& =\frac{\mathrm{RSS}}{1-\frac{\mathrm{TSS}}{2{ }^{2}}} \\
\mathrm{TSS} & =\frac{1-\sum \mathrm{e}^{2}}{\sum \mathrm{yi}}
\end{aligned}
$$

Uji t digunakan untuk menguji signifikan pengaruh masing-masing independent variable (Gujarati, 1999). Ho ditolak apabila $\mathrm{t}$ hitung $>\mathrm{t}$ tabel atau $t$ hitung $<-t$ tabel yang berarti signifikan. Ho diterima apabila $-\mathrm{t}$ tabel $<\mathrm{t}$ hitung yang berarti tidak signifikan.

\section{Hasil dan Pembahasan}

\section{Identitas responden berdasarkan umur}

Karakteristik umur peternak responden di Kecamatan Tegalombo tersaji pada Tabel 2. Penggolongan menurut umur dapat bermanfaat dengan kaitannya perekonomian wilayah. Jumlah penduduk menurut usia dibedakan menjadi dua, yaitu: a) penduduk usia tidak produktif, yaitu penduduk usia 0-14 tahun, dan b) penduduk usia produktif, yaitu penduduk usia 15-65 tahun. Penggolongan tersebut dapat digunakan untuk 


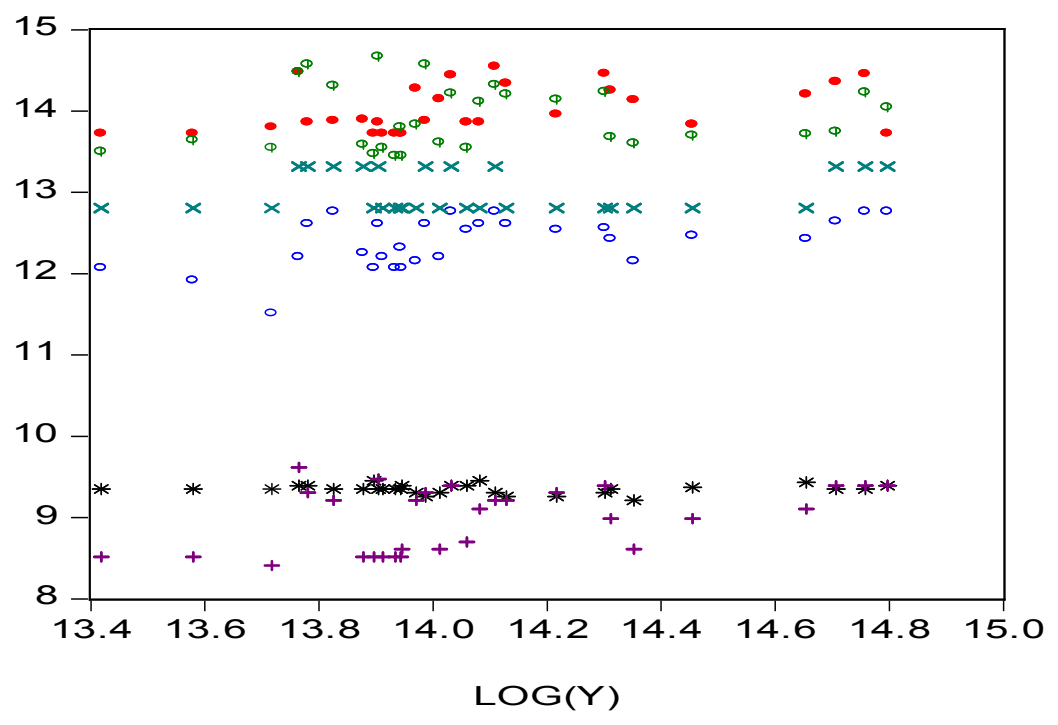

Gambar Scatterplot test.

Tabel 2. Umur peternak responden di Kecamatan Tegalombo, Kabupaten Pacitan (age of the respondent farmers in sub District Tegalombo, Pacitan)

\begin{tabular}{lcc}
\hline \hline Kelompok umur (tahun) (age group (year)) & $\begin{array}{c}\text { Jumlah peternak (orang) (farmers } \\
\text { number (people)) }\end{array}$ & $\begin{array}{c}\text { Persentase (\%) } \\
\text { (percentage (\%) }\end{array}$ \\
\hline $25-40$ & 8 & 26,66 \\
$41-60$ & 18 & 60,00 \\
61 ke atas & 4 & 13,33 \\
Jumlah (sum) & 30 & 100,00 \\
\hline
\end{tabular}

menghitung dependency ratio atau angka ketergantungan (Tarmidi, 1992).

Berdasarkan Tabel 2 dapat diketahui bahwa umur peternak yang terbanyak yaitu 41 tahun ke atas yaitu $60 \%$ dan yang terendah yaitu umur $61 \mathrm{ke}$ atas yaitu $13,33 \%$. Penduduk untuk usia produktif masih dimungkinkan untuk meningkatkan keterampilan dan menambah pengetahuan dalam mengolah usahanya, serta menyerap teknologi baru untuk memajukan usaha ternaknya (Soekartawi et al., 1989).

\section{Biaya produksi pada usaha ternak ayam buras}

Biaya produksi usaha peternakan ayam buras meliputi biaya tetap dan biaya tidak tetap. Rata-rata biaya produksi peternakan ayam buras tersaji pada Tabel 3.

Penyusutan kandang adalah nilai awal pembuatan kandang secara tunai dikurangi nilai akhir kandang tersebut setelah tidak digunakan lagi kemudian dibagi dengan daya tahan kandang. Penyusutan alat nilai awal pembelian alat yang berupa tempat pakan dan tempat minum dikurang nilai akhir alat tersebut setelah tidak digunakan lagi lalu dibagi dengan lama penggunaan alat tersebut. Rerata penyusutan kandang Rp. 29.844,01/tahun atau $0,91 \%$, penyusutan peralatan rata-rata setiap responden peternak adalah $\mathrm{Rp}$. 5.574,50/tahun atau $0,17 \%$.

Biaya listrik dalam setahun rata-rata $\mathrm{Rp}$. $22.733,33 /$ tahun atau $0,69 \%$ dari total biaya produksi. Listrik digunakan sebagai pemanas bagi DOC dan untuk penerangan. Biaya tenaga kerja yang digunakan oleh usaha peternak ayam buras ada tenaga kerja yang dilakukan oleh kalangan keluarga maupun luar keluarga yang diberi upah tertentu. Tenaga kerja dalam keluarga tidak diupah namun diasumsikan berdasarkan jam kerja yang mereka gunakan untuk memelihara ayam buras, kemudian dihitung biaya upah tenaga kerjanya.

Biaya tenaga kerja merupakan biaya rata-rata tenaga kerja yang dikeluarkan oleh peternak yang dinyatakan dalam rupiah persatuan masa usaha peternakan ayam buras dibagi dengan harga output. Pemeliharaan yang baik dan cermat akan memberikan produksi yang baik sehingga meningkatkan keuntungan. Tenaga kerja disamakan dengan biaya tenaga kerja luar keluarga yaitu dengan rata-rata Rp. 7.466,67/jam. Rata-rata pembelian ayam oleh responden selama setahun yaitu Rp. 251.000,00 atau $7,72 \%$ untuk 5 ekor ayam induk. Sebagian besar responden membeli ayam untuk menambah jumlah kepemilikan ayam. Pembelian ayam dilakukan langsung oleh peternak dengan cara menyeleksi 
Tabel 3. Rerata biaya produksi peternakan ayam buras dalam setahun (the average production cost of native chicken poultry farms within one year)

\begin{tabular}{lcc}
\hline \hline \multicolumn{1}{c}{ Komponen biaya (component of cost) } & $\begin{array}{c}\text { Rerata penerimaan (Rp/tahun) } \\
\text { (average revenue (Rp/year)) }\end{array}$ & $\begin{array}{c}\text { Persentase (\%) } \\
\text { (percentage (\%)) }\end{array}$ \\
\hline Biaya tetap (fixed costs) & & \\
Biaya penyusutan kandang (cost of depreciation cage) & $29.844,01$ & 0,91 \\
Biaya penyusutan alat (cost of depreciation tool) & $5.574,50$ & 0,17 \\
Biaya listrik (electricity costs) & $22.733,33$ & 0,69 \\
Biaya tenaga kerja (labor costs) & $454.222,22$ & 13,97 \\
Jumlah (sum) & $512.374,06$ & 15,75 \\
Biaya tidak tetap (variable cost) & & \\
Pembelian ayam (the purchase of chicken) & $251.000,00$ & 7,72 \\
Biaya pakan (cost of feed) & $2.476 .384,83$ & 76,16 \\
Biaya vitamin/obat (vitamin and drugs costs) & $11.508,33$ & 0,35 \\
Jumlah (sum) & $2.738 .893,16$ & 84,24 \\
Total biaya (total costs) & $3.251 .267,22$ & 100,00 \\
\hline
\end{tabular}

dengan tujuan agar mendapatkan ayam jantan serta induk yang mampu menghasilkan anak ayam maupun telur tetas yang baik.

Pembelian pakan merupakan biaya terbesar dari seluruh biaya produksi. Rata-rata biaya pakan dalam setahun yaitu Rp. 2.476.384,83 atau $76,16 \%$ dari total biaya produksi. Biaya pakan menempati urutan terbesar dari total biaya karena tiap hari ternak membutuhkan pakan untuk bertahan hidup dan berproduksi. Hal ini sesuai dengan pendapat Prawirokusumo (1990) bahwa biaya pakan biasanya yang terbesar dalam usaha peternakan yaitu berkisar antara 60 sampai $80 \%$ dari total biaya. Pakan tambahan untuk ayam berupa sisa-sisa dapur dan hijauan seperti bayam yang didapat dari pekarangan rumah.

Biaya vitamin/obat sebesar Rp. 11.508,33 per tahun atau $0,35 \%$. Biaya vitamin dan obat cukup rendah disebabkan adanya bantuan obat dan vitamin gratis dari Dinas Peternakan dan Kesehatan Hewan Kabupaten Pacitan. Rata-rata biaya total untuk peternakan ayam buras mencapai Rp. 3.325.267,22 dengan perincian biaya tetap Rp. 512.374,06 atau $15,75 \%$ dan biaya variabelnya Rp. 2.738.893,16 atau $84,24 \%$. Biaya variabel lebih besar dibanding biaya tetap karena dalam biaya variabel terdapat biaya pakan yang menempati persentase tertinggi atau terbesar dalam biaya total.

\section{Penerimaan peternak}

Penerimaan usaha peternakan ayam merupakan seluruh penerimaan peternakan dari penjualan hasil produksi. Penerimaan diperhitungkan hanya dalam wujud tunai yang diterima oleh responden dari hasil penjualan saja yang diperhitungkan dalam penerimaan.

Pada Tabel 4 dapat dilihat bahwa penerimaan peternak responden meliputi penerimaan dari penjualan ayam buras, penjualan telur dan penjualan kotoran ayam, sebagian besar ayam dijual pada fase ayam muda. Hal ini sesuai dengan tujuan usahanya yaitu untuk pembesaran. Rerata penerimaan responden untuk penjualan ayam muda Rp. 1.799.400,00 atau 38,94\% dari penerimaan total. Penerimaan responden dari penjualan indukan (layer) Rp. 1.113.166,67 atau 24,09\%, dan penerimaan peternak dari hasil induk jantan yaitu $\mathrm{Rp}$. $673.500,00$ atau $14,57 \%$ dari total penerimaan.

Penjualan telur $22,04 \%$ atau rata-rata penerimaan dari penjualan telur oleh responden $\mathrm{Rp}$. 1.018.600,00. Pada tabel 4 terlihat bahwa persentase penjualan ayam lebih besar dibanding dengan penjualan telur dan kotoran ayam.

\section{Pendapatan peternak}

Besarnya pendapatan peternak responden dihitung menggunakan analisis biaya dan penerimaan. Analisis pendapatan diperoleh dari perhitungan selisih antara penerimaan dengan biaya produksi. Pendapatan diperhitungkan secara usahatani.

Hasil analisis pada Tabel 5 tentang pendapatan rata-rata peternak dapat memberikan suatu gambaran yang jelas tentang pentingnya seorang peternak mengembangkan usahanya walaupun dalam usaha tersebut memerlukan biaya produksi yang semakin besar. Biaya produksi yang besar dan seimbang dengan skala usaha maka tingkat pendapatan peternak akan semakin besar pula bila sistem pengelolaannya dilakukan secara optimal (Triana et al., 2007).

\section{Analisis regresi}

Penelitian menggunakan metode regresi linier berganda dalam menguji hipotesis yang diajukan dengan program komputer Eviews 7. Hasil analisis pada Tabel 6 diperoleh persamaan regresi sebagai berikut:

$$
\begin{aligned}
\hat{Y}= & 20,947+0,620 X_{1}+0,003 X_{2}-0,996 X_{3}-0,869 X_{4}- \\
& 0,015 X_{5}+0,845 X_{6}
\end{aligned}
$$


Tabel 4. Rerata penerimaan peternakan ayam buras selama setahun (average of native chicken farm revenue in one year)

\begin{tabular}{lcc}
\hline \hline Komponen penerimaan (component acceptance) & $\begin{array}{c}\text { Rerata penerimaan (Rp) (average of } \\
\text { revenue (Rp)) }\end{array}$ & $\begin{array}{c}\text { Persentase (\%) } \\
\text { (percentage (\%)) }\end{array}$ \\
\hline Penjualan ayam (chicken sales) & & \\
$\quad$ Ayam muda (doc and pullet) & $1.799 .400,00$ & 38,94 \\
$\quad$ Induk betina (hen) & $1.113 .166,67$ & 24,09 \\
$\quad$ Jantan (cock) & $673.500,00$ & 14,57 \\
Sub total & $3.586 .066,67$ & 77,61 \\
Penjualan telur (egg sales) & $1.018 .600,00$ & 22,04 \\
Penjualan kotoran ayam (chicken manure sales) & $15.774,00$ & 0,34 \\
Sub total & $1.034 .374,00$ & 22,38 \\
Total penerimaan (total revenue) & $4.620 .440,67$ & 100,00 \\
\hline
\end{tabular}

Tabel 5. Rata-rata pendapatan peternakan ayam buras selama setahun (average of native chicken poultry farm incomes in one year)

\begin{tabular}{lc}
\hline \hline \multicolumn{1}{c}{ Komponen biaya (component of cost) } & Rerata penerimaan (Rp) (average of revenue (Rp)) \\
\hline A. Biaya tetap: $($ fixed costs) & $512.374,06$ \\
B. Biaya tidak tetap: $($ variable cost $)$ & $2.738 .893,16$ \\
C. Penerimaan revenue & $4.620 .440,67$ \\
Total biaya $(\mathrm{A}+\mathrm{B})($ total costs $(A+B))$ & $3.251 .267,22$ \\
Pendapatan C $-(\mathrm{A}+\mathrm{B})($ incomes $C-(A+B))$ & $1.383 .358,10$ \\
\hline
\end{tabular}

Berdasarkan persamaan tersebut, masingmasing variabel dapat digambarkan pengaruhnya terhadap pendapatan usaha peternakan ayam buras di Kecamatan Tegalombo.

Uji multikolinieritas bertujuan untuk menguji apakah model regresi ditemukan adanya korelasi di antara variabel bebas. Pengujian ini dapat dilakukan dengan melihat nilai koefisien korelasi (r) antar variabel bebas. Widarjono (2007), menjelaskan bahwa multikolinieritas terjadi jika nilai koefisien korelasi antar variabel bebas lebih besar dari 0,85. Nilai koefisien korelasi antar variabel bebas tersaji pada Tabel 7.

Berdasarkan analisis menunjukkan bahwa nilai koefisien antar variabel bebas mempunyai nilai r kurang dari 0,85 sehingga dikatakan bahwa data tidak terjadi multikolinier atau tidak terdapat hubungan antar variabel bebas sehingga asumsi klasik terpenuhi.

Analisis uji asumsi heteroskedastisitas dari hasil output Eview 7 melalui gambar scatterplot menunjukkan pola tertentu dari hasil regresi, maka asumsi tidak heteroskedastisitas dapat ditolak.

Heteroskedastisitas terjadi jika pada scatterplot titik-titiknya mempunyai pola teratur, baik menyempit, melebar maupun bergelombang. Analisis hasil output didapatkan titik-titik menyebar di antara $Y$, dan tidak mempunyai pola yang teratur. Kesimpulan yang bisa didapat adalah variabel bebas di atas tidak terjadi heteroskedastisitas atau bersifat homokendastisitas (Sunyoto, 2009).
Uji F merupakan alat untuk menguji apakah variabel independen berpengaruh secara bersama terhadap variabel dependen. Hasil regresi terhadap variabel pendapatan $(\mathrm{Y})$ dengan variabel lain yaitu pembelian ayam $\left(\mathrm{X}_{1}\right)$, biaya pakan jagung $\left(\mathrm{X}_{2}\right)$, biaya pakan dedak $\left(\mathrm{X}_{3}\right)$, biaya obat/vitamin $\left(\mathrm{X}_{4}\right)$, biaya tenaga kerja $\left(\mathrm{X}_{5}\right)$, biaya listrik $\left(\mathrm{X}_{6}\right)$ diperoleh nilai $F_{\text {hitung }}$ sebesar 7,022 sedangkan $F_{\text {tabel }} 2.55$ sehingga dapat disimpulkan bahwa $\mathrm{F}_{\text {hitung }}$ lebih besar dibanding $\mathrm{F}_{\text {tabel }}$ dengan taraf $\alpha=0,05$. Berdasarkan perhitungan dapat diambil kesimpulan bahwa variabel independen (biaya pembelian ayam, biaya pakan jagung, biaya pakan dedak, biaya obat/vitamin, biaya tenaga kerja, dan biaya listrik) berpengaruh secara bersama-sama terhadap variabel dependen (pendapatan).

Dari hasil regresi diperoleh nilai koefisien determinan $\left(\mathrm{R}^{2}\right)$ sebesar 0,646 berarti bahwa besarnya semua variabel bebas mempengaruhi variabel terikat terhadap pendapatan sebesar $64,6 \%$ yaitu pendapatan ternak ayam yang dipengaruhi variabel-variabel independen yang diteliti (biaya pembelian ayam $\left(\mathrm{X}_{1}\right)$, biaya pakan jagung $\left(\mathrm{X}_{2}\right)$, biaya pakan dedak $\left(\mathrm{X}_{3}\right)$, biaya obat/vitamin $\left(\mathrm{X}_{4}\right)$, biaya tenaga kerja $\left(\mathrm{X}_{5}\right)$, biaya listrik $\left(\mathrm{X}_{6}\right)$ sedangkan sisanya sebesar $35,4 \%$ hasil tersebut diperoleh dari adanya pengaruh yang disebabkan oleh variabel lain di luar atau yang tidak diteliti dari variabel yang diteliti atau dimasukkan dalam kesalahan pengganggu (disturbance's error).

Dari hasil uji $t$ dapat dinyatakan bahwa diduga variabel bebas $\left(\mathrm{X}_{1}, \mathrm{X}_{2}, \mathrm{X}_{3}, \mathrm{X}_{4}, \mathrm{X}_{5}, \mathrm{X}_{6}\right)$ dapat 
Tabel 6. Hasil analisis regresi berganda (multiple regression analysis result)

\begin{tabular}{lccc}
\hline \multicolumn{1}{c}{ Variabel (variable) } & $\begin{array}{c}\text { Koefisien regresi } \\
\text { (regression coefficient) }\end{array}$ & $\begin{array}{c}\text { thitung } \\
\text { tcount }\end{array}$ & $\begin{array}{c}\text { Prob. (sig. } \mathrm{t}) \\
(\alpha=0.05)\end{array}$ \\
\hline $\mathrm{X}_{1}$ (pembelian ayam) (the purchase of chicken) & 0,620 & 2,924 & 0,007 \\
$\mathrm{X}_{2}$ (pakan jagung) (corn) & 0,003 & 0,014 & 0,988 \\
$\mathrm{X}_{3}$ (pakan dedak) (rice bran) & $-0,996$ & $-4,218$ & 0,000 \\
$\mathrm{X}_{4}$ (obat/vitamin) (drugs/vitamin) & $-0,869$ & $-1,040$ & 0,309 \\
$\mathrm{X}_{5}$ (tenaga kerja) (labor) & $-0,015$ & 0,065 & 0,948 \\
$\mathrm{X}_{6}$ (listrik) (electricity) & 0,845 & 3,020 & 0,006 \\
Konstanta (constants) & 20,947 & & \\
F hitung (F count) & 7,022 & & \\
Adjust $\mathrm{R}^{2}$ & 0,554 & & \\
$\mathrm{R}_{\text {Square }}\left(\mathrm{R}^{2}\right)$ & 0,646 & & \\
Variabel terikat $=\mathrm{Y}$ (pendapatan) & & & \\
\hline
\end{tabular}

Tabel 7. Nilai koefisien korelasi antar variabel independen (correlation coefficient between the independent variables)

\begin{tabular}{lcrrrrr}
\hline \hline & LOG $\left(\mathrm{X}_{1}\right)$ & LOG $\left(\mathrm{X}_{2}\right)$ & LOG $\left(\mathrm{X}_{3}\right)$ & $\mathrm{LOG}\left(\mathrm{X}_{4}\right)$ & LOG $\left(\mathrm{X}_{5}\right)$ & \multicolumn{1}{c}{$\operatorname{LOG}\left(\mathrm{X}_{6}\right)$} \\
\hline $\operatorname{LOG}\left(\mathrm{X}_{1}\right)$ & 1,000 & 0,400 & 0,665 & $-0,010$ & 0,565 & 0,751 \\
$\operatorname{LOG}\left(\mathrm{X}_{2}\right)$ & 0,400 & 1,000 & 0,387 & $-0,262$ & 0,286 & 0,601 \\
$\operatorname{LOG}\left(\mathrm{X}_{3}\right)$ & 0,665 & 0,387 & 1,000 & $-0,143$ & 0,664 & 0,841 \\
$\operatorname{LOG}\left(\mathrm{X}_{4}\right)$ & $-0,010$ & $-0,262$ & $-0,143$ & 1,000 & 0,054 & $-0,042$ \\
$\operatorname{LOG}\left(\mathrm{X}_{5}\right)$ & 0,565 & 0,286 & 0,664 & 0,054 & 1,000 & 0,610 \\
$\operatorname{LOG}\left(\mathrm{X}_{6}\right)$ & 0,751 & 0,601 & 0,841 & $-0,042$ & 0,610 & 1,000 \\
\hline
\end{tabular}

mempengaruhi pendapatan (Y). Tingkat signifikasi dari masing-masing koefisien dapat diuji dengan menggunakan uji parsial T-test. Dengan melihat Tabel 6, dapat dijelaskan untuk uji $t$ variabel biaya pembelian ayam $\left(\mathrm{X}_{1}\right)$, jagung $\left(\mathrm{X}_{2}\right)$, dedak $\left(\mathrm{X}_{3}\right)$, obat dan vitamin $\left(\mathrm{X}_{4}\right)$, tenaga kerja $\left(\mathrm{X}_{5}\right)$, dan listrik $\left(\mathrm{X}_{6}\right)$.

Variabel biaya pembelian ayam $\left(X_{1}\right)$. Biaya pembelian ayam $\left(\mathrm{X}_{1}\right)$ mempunyai pengaruh positif terhadap pendapatan dan memperoleh nilai $t_{\text {hitung }}$ sebesar 2,924 dengan $t_{\text {tabel }} 1,895$ maka nilai $t_{\text {hitung }}$ lebih besar dari pada $t_{\text {tabel }}(2,924>1,895)$. Berdasarkan perhitungan tersebut dapat dijelaskan bahwa pembelian ayam berpengaruh terhadap pendapatan. Menurut Cahyono (2011), bahwa harga jual beli ayam buras di pasaran selalu berubah dari waktu ke waktu, hal ini dikarenakan adanya pengaruh dari pangsa pasar, sehingga memberikan pengaruh terhadap pendapatan. Pembelian ayam pada saat harga ayam mengalami kenaikan bisa memberikan pengaruh menurunnya pendapatan.

Variabel biaya pakan jagung $\left(X_{2}\right)$ dan dedak $\left(\mathbf{X}_{3}\right)$. Biaya pakan jagung $\left(\mathrm{X}_{2}\right)$ mempunyai pengaruh positif terhadap pendapatan tetapi berdasarkan uji t tidak berpengaruh signifikan terhadap pendapatan (Y), karena nilai $\mathrm{t}_{\text {hitung }}$ sebesar 0,014 dengan $t_{\text {tabel }}$ yaitu sebesar 1,895 maka nilai $t_{\text {hitung }}$ lebih kecil dari $t_{\text {tabel }}(0,988<1,895)$.

Variabel biaya dedak $\left(\mathrm{X}_{3}\right)$ memberi pengaruh negatif terhadap pendapatan dan diperoleh nilai $\mathrm{t}_{\text {hitung }}$ sebesar $-4,218$ dengan $\mathrm{t}_{\text {tabel }} 1,895$, maka $\mathrm{t}_{\text {hitung }}$ lebih kecil dari $t_{\text {tabel }}(-4,218<1,895)$. Berdasarkan perhitungan tersebut biaya jagung tidak berpengaruh terhadap variabel dependen (pendapatan). Hal ini bisa disebabkan karena peternak juga mempunyai lahan dimana lebih sering ditanami jagung sehingga pakan jagung sebagian besar diambilkan dari panen sendiri. Peternak di Kecamatan Tegalombo Kabupaten Pacitan juga terkadang secara langsung membeli pakan ke petani, mengandalkan sisa hasil pertanian dan limbah hasil rumah tangga sebagai sumber pakan ayam.

Variabel biaya obat dan vitamin $\left(\mathrm{X}_{4}\right)$. Variabel biaya obat dan vitamin $\left(\mathrm{X}_{4}\right)$ memberikan pengaruh positif terhadap pendapatan dan memiliki $t_{\text {hitung }}$ sebesar 1,040 dengan $t_{\text {tabel }} 1,859$ maka $t_{\text {hitung }}$ lebih kecil dari $t_{\text {tabel }}(1,040<1,859)$ Hal ini dapat disimpulkan bahwa biaya obat dan vitamin $\mathrm{X}_{4}$ tidak berpengaruh terhadap pendapatan sesuai dengan pengujian yang hasilnya yaitu non signifikan. Hal ini disebabkan sebagian besar obat dan vitamin yang digunakan berasal dari bantuan Dinas Peternakan dan Kesehatan Hewan Kabupaten Pacitan.

Variabel biaya tenaga kerja $\left(\mathbf{X}_{5}\right)$. Variabel biaya tenaga kerja $\left(\mathrm{X}_{5}\right)$ memberikan pengaruh positif terhadap pendapatan dan memiliki nilai $t_{\text {hitung }}$ sebesar 0,065 dengan nilai $t_{\text {tabel }}$ sebesar 1,895 maka $t_{\text {hitung }}$ lebih kecil dari $t_{\text {tabel }}(0,065<1,859)$. Berdasarkan perhitungan dapat disimpulkan bahwa biaya tenaga kerja $\left(\mathrm{X}_{5}\right)$ tidak berpengaruh terhadap pendapatan. Hal tersebut dikarenakan sebagian besar usaha peternakan masih mempekerjakan 
keluarganya sendiri atau tidak dibayar. Hasil perhitungan tersebut diperoleh berdasarkan asumsi jam orang kerja (JOK). Menurut pendapat Soekartawi (2003), lama waktu bekerja menentukan besar kecilnya biaya tenaga kerja, makin lama jam kerja makin tinggi biaya yang dikeluarkan. Berdasarkan pendapat tersebut lamanya jam kerja yang dipakai peternak berbeda-beda atau bervariasi yang membuat biaya terlalu tinggi dan ada yang rendah.

Variabel biaya listrik ( $\left.\mathbf{X}_{\mathbf{6}}\right)$. Memberikan pengaruh yang positif terhadap pendapatan dan memiliki nilai $t_{\text {hitung }}$ sebesar 3,020 dengan $t_{\text {tabel }} 1,859$ maka $t_{\text {hitung }}$ lebih besar dari $t_{\text {tabel }}(3,020>1,859)$. Berdasarkan perhitungan tersebut biaya listrik hasilnya signifikan karena biaya listrik berpengaruh terhadap pendapatan peternak. Banyak sedikitnya tenaga listrik yang digunakan untuk perkandangan berpengaruh terhadap besar kecilnya biaya yang harus dikeluarkan peternak untuk membayar tagihan listrik.

\section{Kesimpulan}

Pendapatan yang diperoleh peternak ayam buras di Kecamatan Tegalombo Kabupaten Pacitan sebesar Rp. 1.383.358,10/tahun/peternak dari ratarata penjualan 89 ekor, feses dan telur. Faktor produksi yang mempengaruhi pendapatan peternak adalah pembelian ayam dan biaya listrik.

\section{Daftar Pustaka}

Badan Pusat Statistik. 2010. Pacitan dalam Angka Tahun 2010. Pacitan.

Cahyono, B. 2011. Ayam Buras Pedaging. Penebar Swadaya. Jakarta.

Dinas Peternakan dan Kesehatan Hewan Kecamatan Tegalombo. 2009. Kecamatan Tegalombo Dalam Angka 2009. Penerbit Kecamatan Tegalombo. Pacitan.
Gujarati. D. 1999. Basic Econometric. PT Erlangga. Jakarta.

Mardikanto. T. 2001. Manajemen Agroindustri, Kajian Teori dan Model Kelembagaan Agroindustri Skala Kecil Pedesaan. Cetakan 1. UNS Pres. Surakarta.

Prawirokusumo, S. 1990. Ilmu Usahatani. Edisi 2. BPFE. Universitas Gagjah Mada, Yogyakarta.

Sarwono, B. 1992. Beternak Ayam Kampung. Tarsito, Bandung.

Soekartawi, A. Soeharjo, J. Dillon, dan J.B. Hendaker. 1989. Ilmu Usaha Tani dan Penelitian Untuk Petani Kecil. UI Press. Jakarta.

Soekartawi. 2003. Teori Ekonomi Produksi. PT. Raja Grafindo Persada. Jakarta.

Sunyoto, D. 2009. Analisis Regresi dan Uji Hipotesis. Media Pressindo. Yogyakarta.

Tarmidi, L.T. 1992. Ekonomi Pembangunan. PAU. Study Ekonomi. Universitas Indonesia. Jakarta.

Triana, A., T. Salam, dan M. Muis. 2007. Analisis pendapatan usaha peternakan ayam ras petelur periode layer di Kecamatan Cenrana Kabupaten Maros. Jurnal Agrisistem. 3(1): 11-15.

Widarjono. 2007. Ekonometrika: Teori dan Aplikasi untuk Ekonomi dan Bisnis. Ekonisia. Fakultas Ekonomi. UII. Yogyakarta.

Wiguna, M.A. 1993. Usaha Pengembangan Peternakan di Pedesaan. Fakultas Peternakan. UGM. Yogyakarta.

Yuwanta, T., M.A. Wiguna, dan K.A. Santosa. 1999. Pemberdayaan Masyarakat dalam Pembesaran dan Penggaduhan Ayam Buras Sistem Bobot Badan Sebagai Usaha Mengatasi Krisis Ekonomi di Desa Kalibening, Kec. Kalasan, Kab. Sleman. LPM. Universitas Gadjah Mada, Yogyakarta. 